\title{
Internet of Things based Expert System for Smart Agriculture
}

\author{
Raheela Shahzadi \\ Department of Computer Science \\ COMSATS Institute of Information Technology \\ Sahiwal, Pakistan \\ Javed Ferzund \\ Department of Computer Science \\ COMSATS Institute of Information Technology \\ Sahiwal, Pakistan
}

\author{
Muhammad Tausif \\ Department of Computer Science \\ COMSATS Institute of information Technology \\ Vehari, Pakistan \\ Muhammad Asif Suryani \\ Department of Computer Science \\ COMSATS Institute of Information Technology \\ Sahiwal, Pakistan
}

\begin{abstract}
Agriculture sector is evolving with the advent of the information and communication technology. Efforts are being made to enhance the productivity and reduce losses by using the state of the art technology and equipment. As most of the farmers are unaware of the technology and latest practices, many expert systems have been developed in the world to facilitate the farmers. However, these expert systems rely on the stored knowledge base. We propose an expert system based on the Internet of Things (IoT) that will use the input data collected in real time. It will help to take proactive and preventive actions to minimize the losses due to diseases and insects/pests.
\end{abstract}

Keywords-Internet of Things; Smart Agriculture; Cotton; Plant Diseases; Wireless Sensor Network

\section{INTRODUCTION}

Internet of Things (IoT) is a broad term that describes the interconnection of different daily life objects through the internet. In the concept of IoT every object is connected with each other through a unique identifier so that it can transfer data over the network without a human to the human interaction [1, 2]. IoT has referred as a network of everyday objects having ubiquitous computing. The ubiquity of the objects has increased by integrating every object with embedded system for interaction [21]. It connects human and devices through a highly distributed network. IoT is basically the world wide interconnection of devices. The aim of IoT is to connect every person and every object through the internet. In IoT ,every object is assigned a unique identifier, so that every object is accessible through the internet [22][23].

Every object in the IoT has the following three capabilities: awareness, representation, and interaction. Awareness is the ability of the smart objects to understand and sense other objects. Representation is the ability of the objects to present, according to the programming concept. Interaction is the ability to communicate with each other

The IoT is evolving, growing and becoming popular day by day; in the today's world, around 5 billion objects have connected through the internet. In 2020, it has estimated that near about 50 billion objects will be connected to the internet [24]. IoT is providing tremendous opportunities for novel applications, which is now widely used in many aspects of life such as intelligent home monitoring system, products supply chain management, precision agriculture and much more.

Every object in IoT is addressable, recognizable, readable and locatable through the internet by using RFID (Radio Frequency Identification), Wireless Sensor Network (WSN) or other means. The concept of IoT is using many in different domains such as; precision agriculture [1, 2], products supply chain management [3], Smart Grid [4] , environmental monitoring [5], cloud computing [6] and many more. IoT is gaining much importance these days as every object in the network will become a computer [7]. The idea of IoT has become successful due to the invention of recent technologies like sensors, RFID and WSN.

Pakistan is an agricultural country. Although the industry and services sector has transformed Pakistan into a diversified country, still a major part of GDP is contributed by the agriculture sector. The foreign exchange of Pakistan has depended on agricultural products. More than half of the population of Pakistan lives in rural areas and major source of earnings of this population has based on agriculture. Most of the industry in Pakistan is also dependent on agriculture like textile industry, sugar industry, flour industry, juice industry, furniture industry, dairy industry, etc. [2].

Farmers in Pakistan are not aware of the technology and lack agricultural knowledge. They rely on traditional methods and practices. However, the agriculture field in the advanced world has evolved a lot due to the advances in technology and equipment. Pakistan faces huge losses in agriculture due to the following factors.

- Delayed sowing and poor seed quality.

- Environmental hazards.

- Insect and disease attacks.

- Unplanned irrigation and water losses.

- Untimely harvesting.

- Misuse of fertilizer and insecticides. 
- Lack of machinery and equipment.

- Mishandling of ripened crops.

Cash crops have a major share in the economy of Pakistan and cotton crop is very important among them. It is also called as 'white gold'. Heavy losses occur every year due to poor farming practices, attack of pests at different stages and attack of diseases. According to a survey [8], 38 percent loss of cotton crop occurred due to the attack of insects in 2013. According to another survey, due to viral attack ,15 percent loss of cotton crop occurs every year. Cotton crop is affected by some of bacterial and fungal diseases as well as pests and insects. Temperature and humidity requirements for the cotton crop are different from other crops before and after sowing. The timing of spray of insecticides, pesticides, and application of fertilizer also affects the crop growth. So, the continuous monitoring is required to keep the crop healthy.

Most of the farmers in Pakistan are illiterate, and they are unaware of the latest research in the field of agriculture. The farmers normally take guidance from agriculture experts and other experienced farmers. However, the experts are not always available every time and everywhere [9]. So, expert systems have been developed for different crops, fruits and vegetables in the world. Basically an expert system (ES) is a computer program which solves the problems as human being solves the problem. It is a tool which generates output using its knowledge base, so it replicates the behavior of the human. The ES can pinpoint the problems as well as figure out the solutions. It combines the same domain knowledge of different experts. In the ES accumulation of knowledge from different sources is a very important factor.

The ES can provide output whenever it has given input. It means it should be easily available to the farmers. In this paper, we present an Expert System based on the concept of Internet of Things. Sensors will collect data and automatically send it to the ES. The ES will process the information and send the results or decisions to the farmer's mobile phone. In this way, crops can continuously monitor , and timely decisions can be taken. It will help to minimize the losses due to sudden disease and pest attacks through timely proactive and preventive actions. The proposed ES is initially developed for the Cotton crop and evaluated by the farmer community.

The proposed system can be used for.

- Efficient Crop Management. Irrigation Control.

- Environment Warnings and Guidance.

- Optimal usage of fertilizers, insecticides and pesticides

The rest of the paper has organized as follow , in section 2, we discuss the related work. In section 3 we describe proposed ES based on IoT, Section 4 we describe implementation and evaluation of proposed ES based on IoT, In section 5 we describe the results, In section 6 , we elaborate the validity of proposed solution and, In section 7, we conclude the whole work and describe future work.

\section{RELATED WORK}

Fan TongKe [10] proposed the smart agriculture based on cloud computing. The author presented the architecture for the smart agriculture based upon the concept of the IoT and cloud computing. Agriculture information cloud was combined with Internet of Things to achieve the dynamic distribution of resources and balance of the load.

Ji-Chun Zhao et al. [7] studied the applications of IoT in agriculture. The authors proposed a monitoring system based on internet and wireless sensor networks. An information management system was designed to provide the data for research in agriculture. The authors developed software for monitoring of the fields like data acquisition about the fields, data processing models, and system configuration module. The developed application provides accurate control for the monitoring of the green house.

Agrawal and Lal Das [2] discussed the possible future applications and challenges faced by the IoT technology. They presented some key challenges in IoT applications such as: standards, privacy, security, authentication and identification, trust and ownership, integration, coordination, and regulation. They stated that the use of RFID (Radio Frequency Identification), Wireless Sensor Network (WSN) and mobile communication technologies would reduce the gap between theoretical and practical implementations of IoT applications.

Chen and Jin [11] proposed the 'Digital Agriculture' based upon IoT. The working of the digital agriculture is divided into two steps: in the first phase, the information about the temperature, the wind, the soil contents, etc. is collected by different sensors. In the second phase, ZigBee transfers information. The agricultural products has labeled with EPC code. The EPC code reader reads the code of the products.

$\mathrm{Li} \mathrm{Li}$ et al. [4] discussed the application of smart and Wi-Fi based Wireless Sensor Network in IoT. The authors discussed the applications of IoT-based upon Wi-Fi, WSN and smart grid. Smart grid provides the intelligent data collection application, improving reliability of data collection and providing accurate information. IoT provides the intelligent environment monitoring application; water data and air data collected through sensors and sent to server for further processing. They proposed the concept of the precision agriculture. The authors stated that new WSN technology is better as compared to ZigBee.

Hussain et al. [12] proposed the application of Internet of Things (IoT) technology in animal stock chain management. By using the RFID technology, anyone can be tracked or monitored. They discussed some operational principle of IoT. RFID technology is used for the unique identification of objects; each object in the RFID is labeled with EPC code. The authors proposed the use of this technology for maintaining all records for livestock management.

Kosmatos et al. [13] proposed the architecture based on the RFID and smart objects. RFID objects will perform the primitive functionality in the proposed architecture while the smart objects will perform the complex functionality. The architecture was proposed based on the integration of RFID and smart objects. RFID tags have widely used for the identification of objects. So the RFID is used in the proposed architecture for tracking of the objects. The authors used 
service oriented architecture and semantic model-driven approach in the proposed architecture.

Carvin et al. [14] proposed the ubiquitous cognitive management system based on IoT and ubiquitous computing. They presented the problems as well solutions of problems. The basic idea was to use ambient intelligence provided by smart objects to serve the human, improving communication by context information.

Zhou and Zhou [15] proposed a management model based on IoT for visualization and traceability of agricultural products. The aim was to ensure food safety and promote sustainable development of modern agriculture. The authors used the products logistic information along with Internet of Things for effective products supply chain management.

Prasad et al. [16] proposed an expert system for the diagnosis of pests, diseases, and disorders in mango. The system had developed in ESTA (Expert System Shell for Text Animation). In the proposed system, the first step is the knowledge acquisition; the second step is the diagnosis of disease based on the input. They briefly described the type of mango diseases and recommendations for the disease control on the basis by visual symptoms.

Sarma et al. [17] proposed an expert system for diagnosis of disease in rice plant in India. The purpose of the expert system is to assist farmers in solving the problems. The first step is the development of the knowledge base in the form of condition rules. The proposed system is easy to use and will be useful to those people who are unable to get the assistance of some agriculture expert.

Kaliuday et al. [18] proposed rule based expert system for the prevention of pest diseases in rice and wheat crops. They built an expert system (ES) called AgPest for the diagnosis of pest disease in wheat and rice. They developed AgPest in CLIPS. It consists of the IF then else rule for finding the disease. They formulated the rules about the diseases of wheat and rice from different online sources.

Negied [19] proposed the expert system for the protection of the wheat yield in Egypt. The proposed system is developed using following steps; the first step is the problem identification of the domain, the second step is information . They developed the system in MATLAB. The proposed system is helpful for improving the yield of wheat crop and for providing assistance to the farmers in the remote areas.

Kaur et al. [20] proposed the expert system for the detection and diagnosis of the leaf diseases in cereals. It is quite difficult for the farmers to identify the leaf diseases without the assistance of the experts. For the identification of the diseases, they proposed image comparison techniques in JAVA. They used techniques like affine transformation and edge detection for this purpose. It is web based expert system so that it can be accessible from any web-enabled system

\section{A. Expert System in Agriculture}

Expert system (ES) is the branch of artificial intelligence that deals with the development of computer programs which can solve the problems as the human beings solve the problems [25]. The application of expert system in agriculture is increasing widely since many years. A number of expert systems have been developed in the field of agriculture such as

- AMRAPALIKA is the ES for the diagnosis of disease, pest and disorders in Indian mango [16]

- An expert system for diagnosis of disease in Indian rice plant[4].

- CITEX: An expert system for citrus crop management[26].

- CUPTEX: An expert system proposed for the management of cucumber[27].

- An expert system for the olive crop diseases and weed identification in Spain[9].

- LIMEX: An expert system for the management of lime crop[28].

- CALEX: An expert for the diagnosis of peach and nectarine disorders[29].

- CITPATH: An expert system for the diagnosis of fungal disease in citrus fruit[30].

The first step in the development of any ES is the problem identification. For example, if we are developing the ES for cotton crop then symptoms are identified. The description of the diseases can be textual or in the form of images. After that rules are formulated based on the concept of if then else structure.

Most of the farmers in the remote areas are illiterate not having proper knowledge of dealing with diseases. Some diseases of the crops are difficult to distinguish because two or more diseases have the same symptoms. So, it creates problems for the farmers. This problem can overcome with the help of ES by combining the knowledge of different experts in one application. Most of the researchers are trying to develop the ES for fulfilling the needs of the farmers. If farmers. The farmer gets the assistance in time, the productivity rate of the crops will increase

\section{IOT BASED EXPERT SYSTEM}

For overcoming the problems of agriculture, we develop an initial framework based on IoT. The proposed solution consists of three main components the first component is the deployment of sensors in the field; we deploy soil sensors, humidity sensors, and temperature and leaf wetness sensors in the fields. Sensors collect the data and send it to sever, on the serve side we deploy the expert system, which processes the data and send the recommendations to the farmers about crops.

\section{A. Deployment of Sensors}

The sensors have deployed in the fields for the collection of data about the environment, humidity, soil moisture and leaf wetness. For the collection of data waspmote agriculture sensor board is used because it is specially designed for handling agriculture activities. The sensor board consists of AT mega 1281 microprocessor and 2GB micro SD -card. Every sensor board consists of four different types of sensors, the soil sensor, humidity sensor, temperature sensor and leaf wetness sensors. 
We use three soil sensors, temperature sensors, humidity sensors and leaf wetness receptively for a precise and accurate measure of soil contents, environmental temperature, the humidity level in the environment and leaf wetness at the same time. The communication module XBee-802.15.4 is present in wasp-mote agriculture board. It can communicate with microcontroller at the rate of 38400 bps. The range of transmission is near about 500 meters. The gateway is the bridge between sensor nodes and server. It can communicate wirelessly with the sensor and through USB port with a computer. We conducted this experiment under controlled environmental conditions. The overall architecture of sensors communication has described in Fig 1

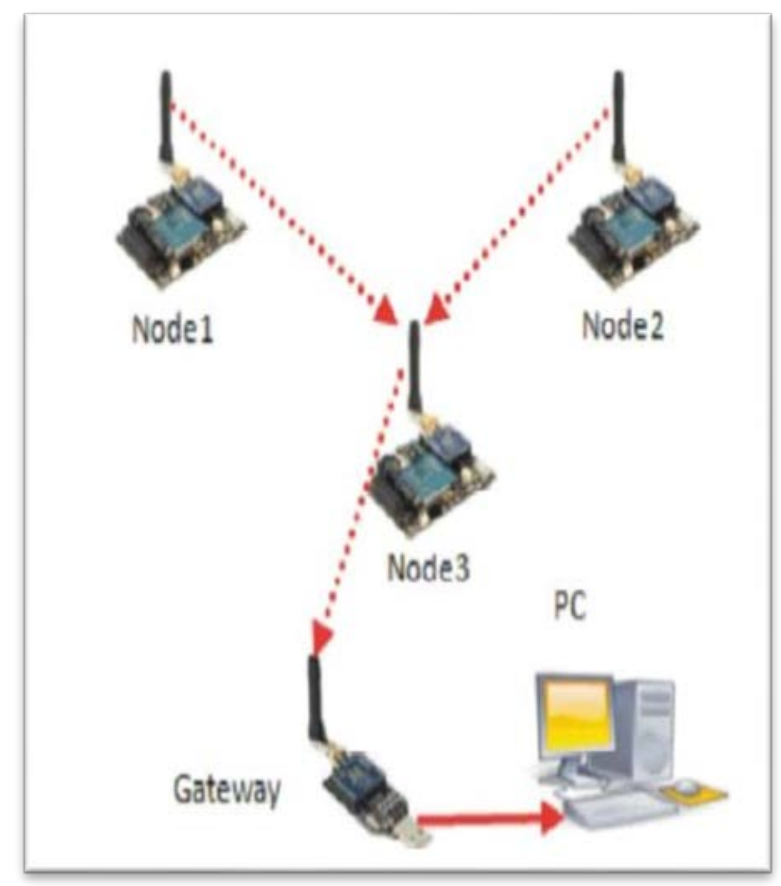

Fig. 1. Communication of Sensors Data in IoT Based ES

\section{B. IoT-Based Expert System for Cotton Crop}

IoT-based Expert System is different from traditional Expert Systems regarding inputs. It uses real-time input data gathered with the help of sensors. The sensor nodes send data to the gateway after the defined interval of time. The server receives data through the USB port. For storing and copying the cool term software, is used. The expert system deploys in the server process the data and sends the recommendation to the farmer cell phone. For solving this problem, the expert system based on the concept of IoT has proposed in Fig 2.

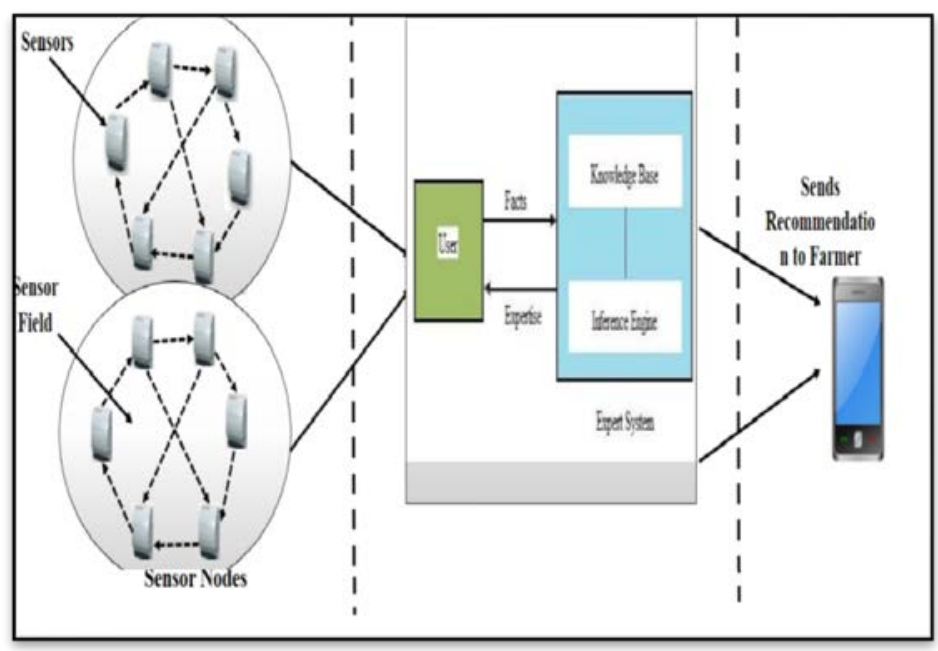

Fig. 2. IoT Based Expert System

The rest of the working of the proposed ES is similar to the traditional Expert Systems. It is implemented using CLIPS (C Language Integrated Production System) developed by NASA [31]. CLIPS is a C based instead of LISP and supports three programming approaches: rule-based, object oriented and procedural. It is portable, extendable, can be easily integrated and supports interactive development. It also has features for verification and validation of expert systems. The proposed expert system consists of the following main components.

- Knowledge Base

- Inference Engine Agenda

- Working Memory

- Explanation Facility

- User Interface

The structure of the expert system has shown in Fig 3.

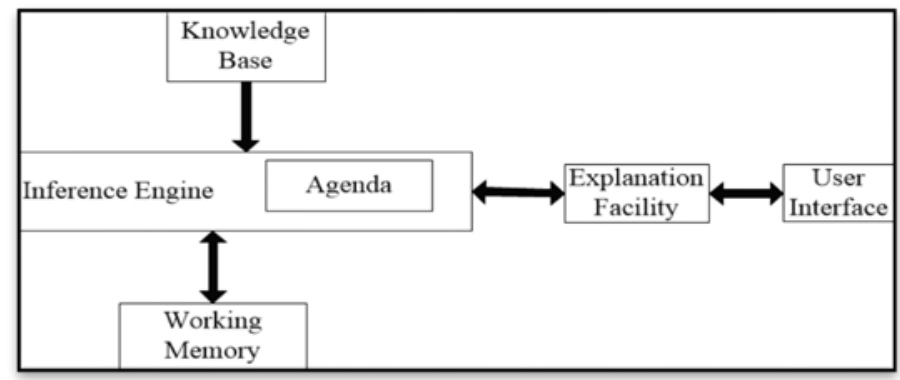

Fig. 3. Expert System in CLIP

The first step in the development of expert system is the knowledge acquisition of the domain. The most important thing in the knowledge acquisition is what type of knowledge we require for the expert system. In the proposed system, we need data about pests, insects, diseases, weeds and growth environment required for cotton crops. The knowledge acquisition can have accomplished in three ways.

- Experts of the domain are interviewed. 
- Research articles about the domain are reviewed.

- Information is obtained by field observations.

Field observation may not be much stronger, as being computer scientist we are unaware about the diseases. Another thing which makes the field observation weak is that, all types of diseases, pests, weeds and insects are not spotted on the cotton crop at the same time. We gather the majority of the information by conducting interviews with experts. We get information about the type of diseases, causes of diseases, symptoms of diseases, the insects which attack on the cotton crop, the weeds which destroy the cotton crop, and the insects which spread the disease from one plant to another.

Different sensors collect the data, soil sensors collect the data about soil condition, soil moisture and soil content, while weather sensors collect the data about humidity and temperature. Sensors send the data to the server, the server decides about the diseases on the basis of the fact list which is used for the training. In CLIPS, fact list, rule list, and agenda with the activation list kept in memory. All the facts have based on simple if then else logic. The sensors collect data and send to the server, on the server side, we deploy the expert system which processes the data and analyzes the data and send the recommendation to the farmer about crops.

\section{Server Send Recommendation to Farmer}

The server processes the sensor data, after processing it send the recommendation to the farmer cell phone. So, for farmer convenience, we develop an android app for farmers. Farmers install the android app on their phone. The server sends the recommendation to the farmer cell phone. The server sends the recommendation in English; farmer can can covert the recommendation to the Urdu or Punjab in his convenient language.

\section{IMPLEMENTATION AND EVALUATION}

This section describes the implementation and evaluation of the expert system for SA. The sensors collect the real-time data and send to the server. On the server side, ES have deployed for extracting the information from sensor data.

\section{A. Expert System for CLIPS}

In this section, we implement different fact list of insect diagnosis, pest diagnosis, weeds diagnosis and irrigation scheduling.

Table 1 describes the different fact lists of insects, pest symptoms and recommendation for the attack of insect pest.

Table 2 describes the different fact lists of weed symptoms and recommendations for the attack of weeds.

Table 3 describes the different fact lists of sucking insects and recommendation for the attack of sucking insects.
The irrigation of crops depends on several factors like soil moisture, soil type, depth of root zone and the environment. Every soil has different physical properties and textures like coarse soil, medium texture, soil and heavy fine textured soil. The water capacity of every soul is different, so the amount of irrigation also varies according to the texture of the soil. Environmental fluctuations are also important factors for scheduling of irrigation. The cotton crop has a specific limit of water depletion, if the water gets depleted more than the specified threshold limit, then irrigation should be applied. To calculate the minimum flow of irrigation q (in cubic meters per hour), we used Equation 1. In this equation, Dg is gross application dose, A is an area, I is interval of day, $\mathrm{T}$ is operating hour per day and 10 is a constant for hectare. In equation 1 we are presenting a formula for calculating the irrigation dose.

$$
\mathrm{q}=10 A * D g / I+T \text {. }
$$

Table 4 describes the irrigation scheduling in the cotton crops.

\section{RESULTS}

We conduct this experiment in the cotton fields Sahiwal from June 2015 to December 2015. The server processes the data and sends the recommendation to the farmer. The proposed ES provide diagnose diseases, attack of weeds and attack of pests, it provides the pesticide recommendation for weeds, diseases, and pests. It provides predication of diseases based on sensor data. It provides irrigation scheduling based on temperature and soil contents; it can also provide the dose of irrigation.

After that sensors send data to the server, on the server side, we deploy the expert system which processes the sensor data and sends the recommendation to the farmers.

Table 5 describes the comparison of the expert system, which has presented during different eras. In the previous expert system, the user manually inputs the symbol of diseases, and they use web-based, ontology based and expert system tool for the development of expert systems. In previous literature, they did not use the concept of IoT for the collection of data. In our proposed solution, we develop an expert system based on the concept of IoT. Different kind of sensors is deployed in the fields which monitor the crops, and send the data to the server, server process the data and send a recommendation to the farmer.

Fig 4 represents the relationship between temperature and humidity sensor data, temperature, and humidity, inversely proportional to each other. If temperature increase then humidity level decrease. We are just representing the 117 recording of sensor data. By taking these sensor data, we are scheduling the automatic irrigation. 
TABLE I. INSECT SYMPTOMS AND INSECTICIDES RECOMMENDATION

\begin{tabular}{|c|c|c|}
\hline Insects Symptoms & Insect Diagnosed & Insecticides Recommendation \\
\hline $\begin{array}{l}\text { If location=underside of leaves and body } \\
\text { color=yellowish and wing color=white then } \\
\text { insectpest diagnosed. }\end{array}$ & IF ?insectpest= Whitefly & $\begin{array}{l}\text { Then } \\
(\text { ?insecticides }=\text { Polo500SC } \wedge \text { ?dose }=250 \mathrm{ml}) \wedge \\
(\text { insecticides }=\text { Confidor200SL } \wedge \text { ?dose }=250 \mathrm{ml}) \wedge \\
(\text { ?insecticides }=\text { Mospilan200SP } \wedge \text { ?dose }=5 \mathrm{gm}) \wedge \\
\text { (?insecticides }=\text { Danitol30EC } \wedge \text { ?dose }=200 \mathrm{ml} \\
\text { And Use Neem Leaf Extract }\end{array}$ \\
\hline $\begin{array}{l}\text { If temp=warm and shape=spindle shaped and } \\
\text { wings=elongated then Thrips diagnosed. }\end{array}$ & IF ?insectpest=Thrips & $\begin{array}{l}\text { Then } \\
(\text { ?insecticides }=\text { Confidor } 200 \mathrm{SL} \wedge \text { ?dose }=80 \mathrm{ml}) \wedge \\
(\text { ?insecticides }=\text { Confidor70WS } \wedge \text { ?dose }=5 \mathrm{gm} / \mathrm{kg} \text { seed }) \wedge \\
(\text { ?insecticides }=\text { Mospilan } 20 \mathrm{SP} \wedge \text { ?dose }=5 \mathrm{gm}) \wedge \\
(\text { ?insecticides }=\text { Thiodan } 35 \mathrm{EC} \wedge \text { ?dose }=600 \mathrm{ml})\end{array}$ \\
\hline 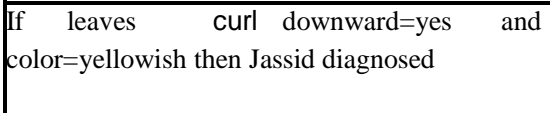 & IF ?insectpest=Jassid & $\begin{array}{l}\text { Then } \\
\text { ?insecticides }=\text { Baythroid TM } 525 \mathrm{EC} \wedge \text { ?dose }=100 \mathrm{ml}) \wedge \\
(\text { ?insecticides }=\text { Nurelle D 505EC } \wedge \text { ?dose }=500 \mathrm{ml})\end{array}$ \\
\hline
\end{tabular}

TABLE II. WEEDS SyMPTOMS AND PESTICIDES RECOMMENDATION

\begin{tabular}{|l|l|l|}
\hline Weeds Symptoms & Weeds Diagnosed & Herbicide Recommendation \\
\hline $\begin{array}{l}\text { If stem type=slender and structure=smooth } \\
\text { and height=24 inch }\end{array}$ & If ?weeds= sedges & Then \\
$\begin{array}{l}\text { and } \\
\text { leafcolor=yellowgreenandleaf } \\
\text { structure=flat then sedge weed diagnosed }\end{array}$ & & ?herbicide=Stomp 330EC \\
\hline
\end{tabular}

TABLE III. WORMS SYMPTOMS AND INSECTICIDES RECOMMENDAITON

\begin{tabular}{|c|c|c|}
\hline Worms Symptoms & Worms Diagnosed & Insecticides Recommendation \\
\hline $\begin{array}{l}\text { If symptoms =chewed holes and } \\
\text { caterpillars=white and larvae= yellow } \\
\text { then Cotton bollworm diagnosed. }\end{array}$ & $\begin{array}{l}\text { If ?insect=American } \\
\text { BollWorm }\end{array}$ & $\begin{array}{l}\text { Then } \\
(\text { insecticides }=\text { Procalim 019EC } \wedge \text { ?dose }=200 \mathrm{ml}) \wedge \\
(\text { insecticides }=\text { Larvin 80DF } \wedge \text { ?dose }=450 \mathrm{gm}) \wedge \\
(\text { insecticides }=\text { Tracer } 240 \mathrm{SC} \wedge \text { ?dose }=80 \mathrm{ml}) \wedge \\
(\text { insecticides }=\text { Shogan } 1.8 \mathrm{EC} \wedge \text { ?dose }=250 \mathrm{ml}) \wedge \\
(\text { insecticides }=\text { Deltaphos } 360 \mathrm{EC} \wedge \text { ?dose }=700 \mathrm{ml}) \\
(\text { insecticides }=\text { Match } 050 \mathrm{EC} \wedge \text { ?dose }=800 \mathrm{ml})\end{array}$ \\
\hline $\begin{array}{l}\text { If color= light brown and rain in } \\
\text { August= Yes and Rain in September= } \\
\text { Yes rhen Pink BollWorm diagnosed. }\end{array}$ & If ?insect=Pink BollWorm & $\begin{array}{l}\text { Then } \\
(\text { ?insecticides }=\text { Deltaphos } 360 \mathrm{EC} \wedge \text { ?dose }=600 \mathrm{ml}) \wedge 2.5 \mathrm{EC} \\
\wedge \text { ?dose }=400 \mathrm{ml}) \wedge \\
\text { (?insecticides }=\text { Talstar10 EC } \wedge \text { ?dose }=250 \mathrm{ml}) \\
\text { (?insecticides }=\text { Karate }\end{array}$ \\
\hline $\begin{array}{l}\text { if rainfall= high and time }>=\text { July and } \\
\text { time }<=\text { September and wings }=\text { four and } \\
\text { streak =one white then Spotted Boll } \\
\text { Worms Diagnosed. }\end{array}$ & If ?insect=Spotted bollworms & $\begin{array}{l}\text { Then } \\
\text { (?insecticides }=\text { Deltaphos } 36 \mathrm{EC} \wedge \text { ?dose }=600 \mathrm{ml}) \wedge \\
(\text { insecticides }=\text { Karate } 2.5 \mathrm{EC} \wedge \quad \text { dose }=400 \mathrm{ml}) \wedge \\
\text { (?insecticides }=\text { Match } 50 \mathrm{EC} \wedge \quad \text { ?dose }=800 \mathrm{ml}) \wedge \\
\text { (?insecticides }=\text { Talstar } 10 \mathrm{EC} \wedge \quad \text { ?dose }=250 \mathrm{ml}) \wedge \\
(\text { insecticides }=\text { Sumi Alpha } 110 \mathrm{EC} \wedge \text { ?dose }=200 \mathrm{ml})\end{array}$ \\
\hline
\end{tabular}

TABLE IV. IRRGATION SCHEDULING IN COTTON CROP BASED ON EXPERT SYSTEM

\begin{tabular}{|l|l|l|}
\hline & Fact Regarding Scheduling & Irrigation Scheduling \\
\hline 1 & $\begin{array}{l}\text { If crop=cotton and area=1.5ha and growing season }> \\
\text { =August and growing season }<=\text { December and Soil } \\
\text { Texture=99mm/m Then }\end{array}$ & $\begin{array}{l}\text { Then } \\
\text { Irrigation method= Pressured piped surface method }\end{array}$ \\
\hline 2 & $\begin{array}{l}\text { If month=August and Time=beginning of August and pre } \\
\text { sowing irrigation=0.6m }\end{array}$ & $\begin{array}{l}\text { Then } \\
\text { Irrigation After=2 days and irrigation=crop establishment }\end{array}$ \\
\hline 3 & If month=August and Time=8 August & $\begin{array}{l}\text { Then } \\
\text { Irrigation After=2 days and irrigation=425m3 }\end{array}$ \\
\hline 4 & If month=August and Time=16 August & $\begin{array}{l}\text { Then } \\
\text { Irrigation After=2 days and irrigation=425m3 }\end{array}$ \\
\hline 5 & If month=August and Time=24 August & $\begin{array}{l}\text { Then } \\
\text { Irrigation After=2 days and irrigation=425m3 }\end{array}$ \\
\hline 6 & If month= September and Time=1 September & $\begin{array}{l}\text { Then } \\
\text { Irrigation After=5days and irrigation=891m3 }\end{array}$ \\
\hline 7 & If month= September and Time=1 September & $\begin{array}{l}\text { Then } \\
\text { Irrigation After=5days and irrigation=891m3 }\end{array}$ \\
\hline 8 & If month= September and Time=11 September & Then \\
\hline
\end{tabular}




\begin{tabular}{|l|l|l|}
\hline & & Irrigation After=5days and irrigation=891m3 \\
\hline 9 & If month= September and Time=22 September & $\begin{array}{l}\text { Then } \\
\text { Irrigation After=5days and irrigation=891m3 }\end{array}$ \\
\hline 10 & If month= October and Time=2 October & $\begin{array}{l}\text { Then } \\
\text { Irrigation After=5days and irrigation=75m3 }\end{array}$ \\
\hline 11 & If month= October and Time=11 October & $\begin{array}{l}\text { Then } \\
\text { Irrigation After=5days and irrigation=75m3 }\end{array}$ \\
\hline 12 & If month= October and Time=21 October & $\begin{array}{l}\text { Then } \\
\text { Irrigation After=5days and irrigation=75m3 }\end{array}$ \\
\hline 13 & If month= October and Time=31 October & $\begin{array}{l}\text { Then } \\
\text { Irrigation After=5days and irrigation=75m3 }\end{array}$ \\
\hline 14 & If month= November and Time=13 November & $\begin{array}{l}\text { Then } \\
\text { Irrigation After=5days and irrigation=75m3 }\end{array}$ \\
\hline 15 & If month= November and Time=26 November & $\begin{array}{l}\text { Then } \\
\text { Irrigation After=5days and irrigation=75m3 }\end{array}$ \\
\hline
\end{tabular}

TABLE V. COMPARISON OF PROPOSED IOT BASED EXPERT SyStem WITH OTHER ES

\begin{tabular}{|c|c|c|c|c|c|c|}
\hline$\frac{d}{\vec{E}}$ & ? & 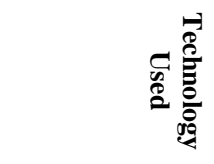 & 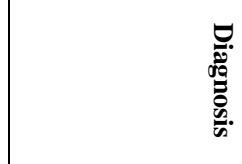 & 总 & 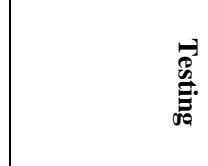 & 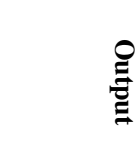 \\
\hline 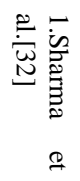 & 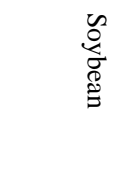 &  & 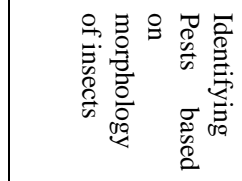 & 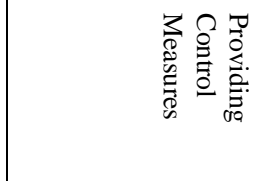 & 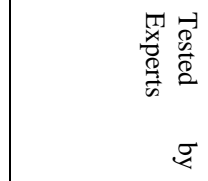 & 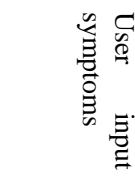 \\
\hline  & 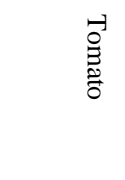 & 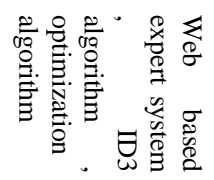 & 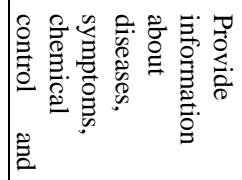 & 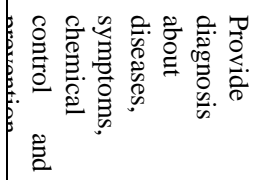 & Z & 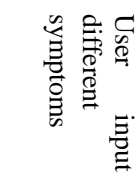 \\
\hline 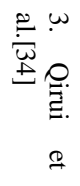 & 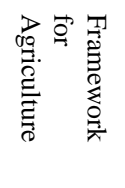 & 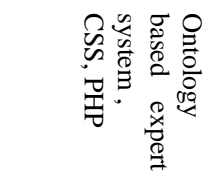 &  & Z & Z & Z \\
\hline 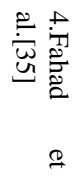 & $\sum_{0}$ & 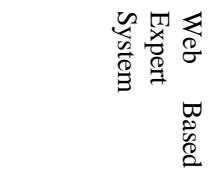 & 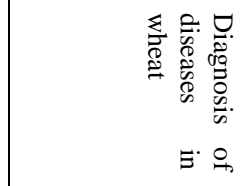 &  & Z & 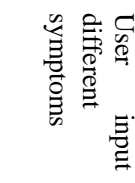 \\
\hline 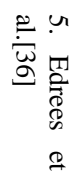 & 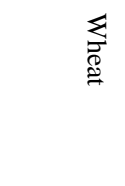 & $\frac{\mathscr{N}}{\stackrel{\mathscr{J}}{=}}$ & 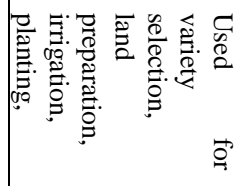 & 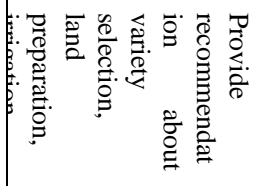 &  & 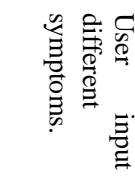 \\
\hline 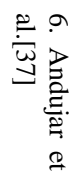 & 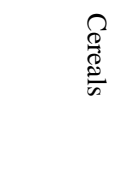 & 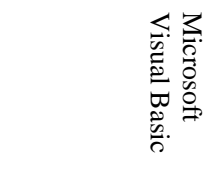 & 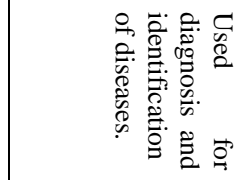 & 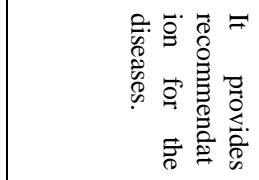 & 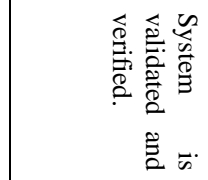 & 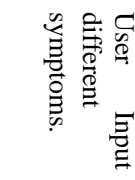 \\
\hline 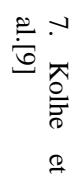 & 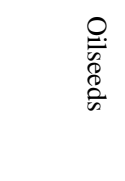 & 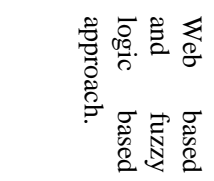 & 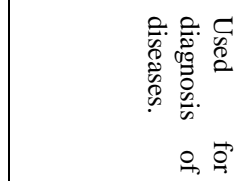 & 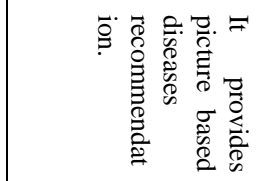 & 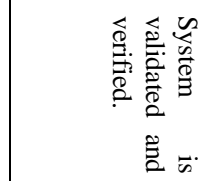 & 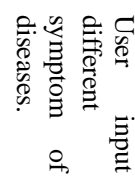 \\
\hline
\end{tabular}




\begin{tabular}{|c|c|c|c|c|c|c|}
\hline  & 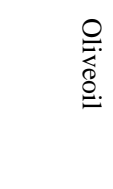 & 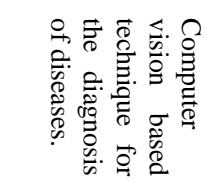 & 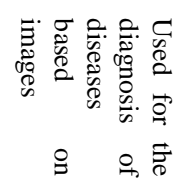 &  & 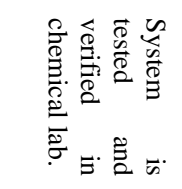 & 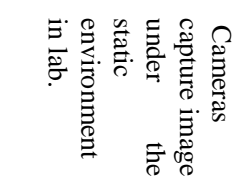 \\
\hline 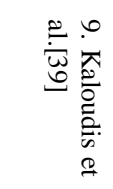 & 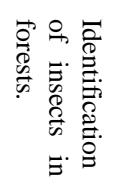 & 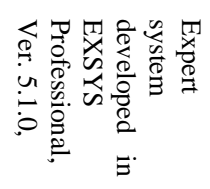 & 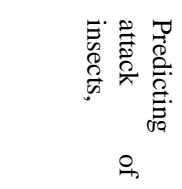 & 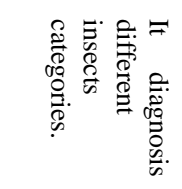 & 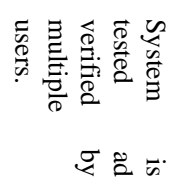 & 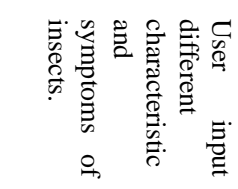 \\
\hline 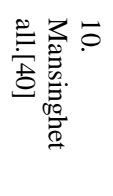 & 尺 & 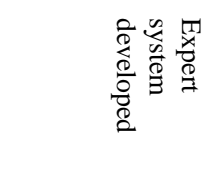 & 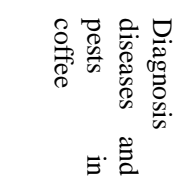 & 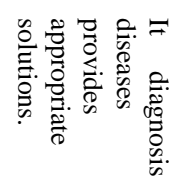 &  & 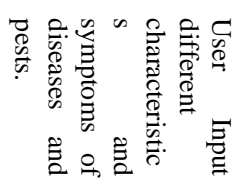 \\
\hline 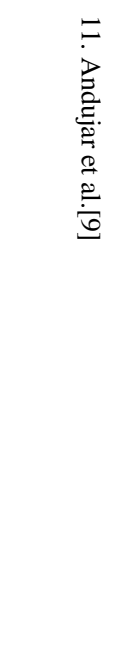 & 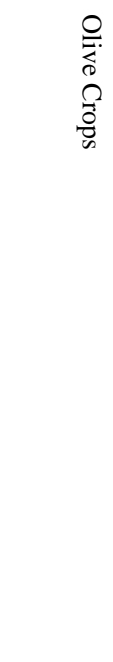 &  & 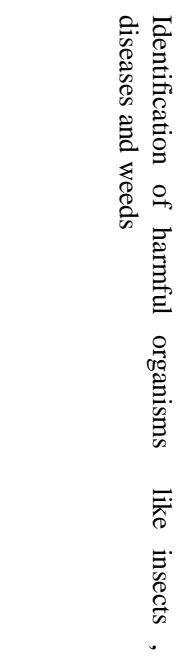 & 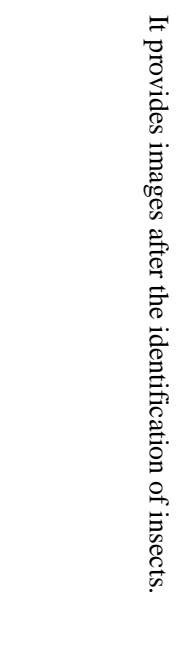 & 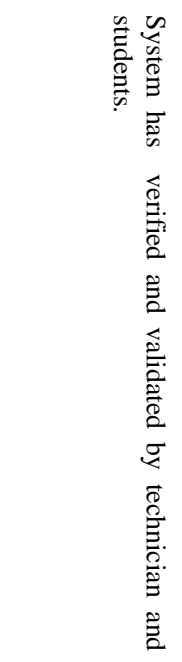 & 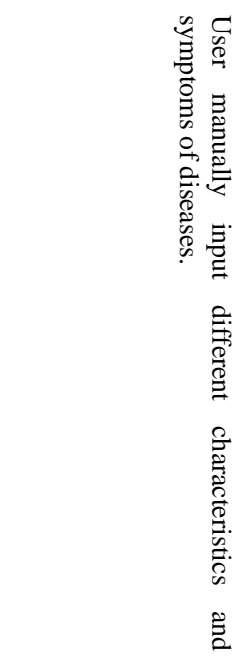 \\
\hline
\end{tabular}

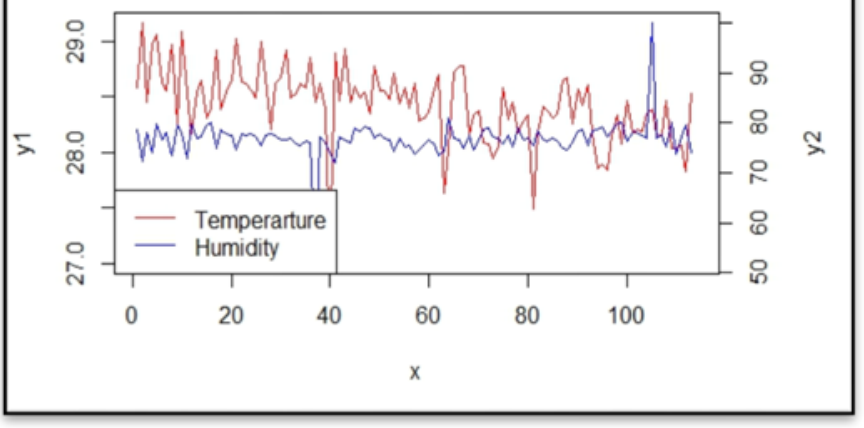

Fig. 4. Comparison of Temperarture Sensor and Humidity Sensors Data

Fig 5 represents the relationship between soil moisture and leaf wetness data; these are directly proportional to each other. If the soil moisture increases then leaf wetness will increase automatically.

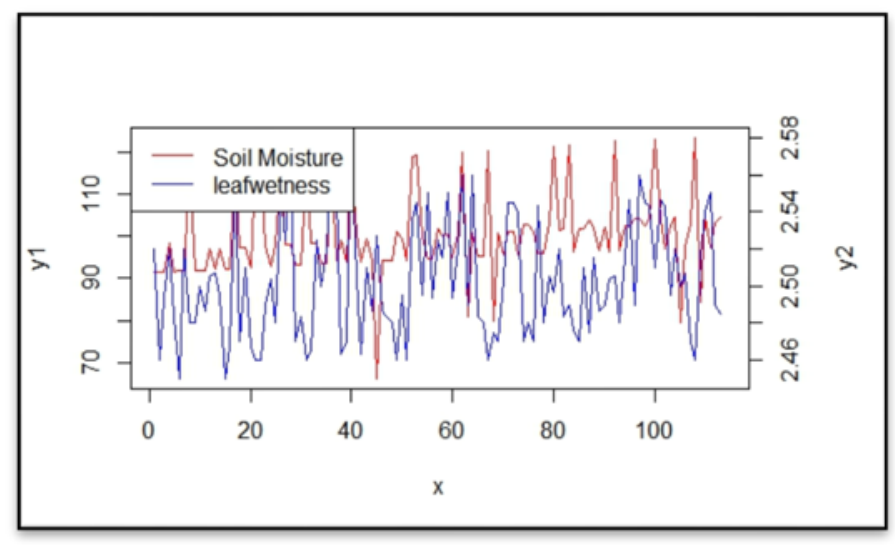

Fig. 5. Comparison of Soil Moisture Sensor and Leaf Wetness Sensor Data

\section{VALIDITY OF PROPOSED SOLUTION}

Our proposed solution is not so much costly as one may think due to the costly deployments of the sensors and actuators in the field. It is a fact that farmers invest heavily on electricity, fertilizers, insecticides, and pesticides. They are using these resources efficiently because they are unaware of the actual needs of the cotton crop. This investment can minimized by one-time investment on sensors. The sensors and cameras can monitor the cotton crop 24/7 and provide input for 
proactive actions and optimal use of resources like water, fertilizer, insecticides and pesticides. Before deploying the IoTbased ES, we conduct the survey from users either they are willing to accept the IoT-based ES for agriculture. In our survey 100 different respondents like farmers, experts of agriculture participate in it. Farmers in Pakistan are illiterate, so we conduct surveys to ensure framework feasibility of its implementation, to evaluate the need of the system, after effects and their tradeoff while using IoT-based ES.

\section{CONCLUSION}

In this paper, we have presented an ES for Cotton crop based on the concept of IoT. We tried to develop and initial frame for IoT-based agriculture. We developed an IoT-based ES. It's based ES consists of three modules; the first part consists of the deployment of WSN in the cotton fields. WSN has used for the monitoring of the cotton crop condition. The Waspmote agriculture sensor board has used for the monitoring of the cotton crop condition. It consists of temperature sensors, humidity sensors, leaf wetness sensors and soil sensors.

In the concept of the IoT, the server should send the commands to the actuators of the fields, so the actuators of fields can take appropriate decisions. The sever should be intelligent enough to take decisions appropriately. For this purpose, we deploy an ES so that it can make decisions automatically. In Table 5 describes that different ES developed during a different era, but in this paper, we combine the IoT and ES. The sensors send the data to the server on the server side; we deployed the ES, which process and analyzes the sensor data. The data is fed to the ES that analyses it using the knowledge base and produces findings and recommendations. The ES consists of user interface, knowledge base and inference engine. On the server side, we deploy the concept of smart irrigation. Sensors monitor the soil moisture, leaf wetness, temperature, and humidity level in the environment and send the recommendation to the farmer about the irrigation in the cotton crop. In this paper, we ES for identification of different weeds, pests and different insects which attack on the cotton crop. These findings are sent to the farmer's mobile phone for taking necessary actions in the field. We proposed an initial framework for the working of Smart Agriculture (SA).

Before developing the concept of SA we conduct the survey and ask form user either the proposed system will be accepted by users or not. In this survey, we also ask from farmers and experts the flaws of the current system and whether they are satisfied the working of current agriculture or not. After that proposed system was evaluated by 100 different users like farmers and experts of Agri domain and 65 percent of respondents are satisfied with the working of SA and they are willing to accept the concept of SA. As we know farmers are illiterate in Pakistan so that we get 65 percent results. By deploying the IoT-based ES the productivity rate of the cash crops can be increased and problem of farmers also be reduced The proposed system was evaluated by 100 experts from the field and was found helpful for the farmers.

\section{FUTURE WORK}

In this paper, we present an initial framework for the diagnosis weeds, insects and different pests in cotton crop. We also deployed the concept of Smart Irrigation in cotton crop. For this purpose, we deploy the ES.

In the future we will try to deploy the actuators in the fields and we enhance the functionality of server by deploying genetic algorithm, artificial neural network and digital image processing techniques on the server. We can diagnose the diseases in a better way if we deploy the cameras in the fields.

\section{REFERENCE}

[1] Morais, Raul, A. Valente, and C. Serôdio. "A wireless sensor network for smart irrigation and environmental monitoring: A position article." In 5th European federation for information technology in agriculture, food and environement and 3rd world congress on computers in agriculture and natural resources (EFITA/WCCA), pp.45-850. 2005.

[2] Agrawal, Sarita, and Manik Lal Das. "Internet of Things-A paradigm shift of future Internet applications." In Engineering (NUiCONE), 2011 Nirma University International Conference on, pp.1-7. IEEE, 2011.

[3] Hu, Xiangyu, and Songrong Qian. "IoT application system with crop growth models in facility agriculture." In 2011 6th International Conference on Computer Sciences and Convergence Information Technology ICCIT. 2011.

[4] Li, Li, Hu Xiaoguang, Chen Ke, and He Ketai. "The applications of WiFi-based wireless sensor network in internet of things and smart grid." In Industrial Electronics and Applications ICIEA, 2011 6th IEEE Conference on, pp. 789-793. IEEE, 2011.

[5] Tuli, Anupriya, Nitasha Hasteer, Mukesh Sharma, and Ankur Bansal. "Framework to leverage cloud for the modernization of the Indian agriculture system." In Electro/Information Technology (EIT), 2014 IEEE International Conference on, pp. 109-115. IEEE, 2014.

[6] Liu, Yuxi, and Guohui Zhou. "Key technologies and applications of internet of things." In Intelligent Computation Technology and Automation (ICICTA), 2012 Fifth International Conference on, pp. 197200. IEEE, 2012.

[7] Zhao, Ji-chun, Jun-feng Zhang, Yu Feng, and Jian-xin Guo. "The study and application of the IOT technology in agriculture." In Computer Science and Information Technology ICCSIT, 2010 3rd IEEE International Conference on, vol. 2, pp. 462-465. IEEE, 2010.

[8] Jhuria, Manoj, Ajit Kumar, and Rushikesh Borse. "Image processing for smart farming: Detection of disease and fruit grading." In Image Information Processing (ICIIP), 2013 IEEE Second International Conference on, pp.21-526. IEEE, 2013.

[9] González-Andújar, José Luis. "Expert system for pests, diseases and weeds identification in olive crops." Expert Systems with Applications 36, no. 2,pp 3278-3283,2009.

[10] TongKe, Fan. "Smart Agriculture Based on Cloud Computing and IOT." Journal of Convergence Information Technology 8, no. 2 ,2013.

[11] Chen, Xian-Yi, and Zhi-Gang Jin. "Research on key technology and applications for internet of things." Physics Procedia 33, pp. 561-566, 2011.

[12] Talpur, Mir Sajjad Hussain, Murtaza Hussain Shaikh, and Hira Sajjad Talpur. "Relevance of Internet of Things in Animal Stocks Chain Management in Pakistan's Perspectives." International Journal of Information and Education Technology 2, no. $1,2012$.

[13] Evangelos A, Kosmatos, Tselikas Nikolaos D, and Boucouvalas Anthony C. "Integrating RFIDs and smart objects into a UnifiedInternet of Things architecture." Advances in Internet of Things $2011,2011$.

[14] Carvin, Denis, Philippe Owezarski, and Pascal Berthou. "Managing the upcoming ubiquitous computing." In Proceedings of the 8th International Conference on Network and Service Management, pp. 1276-280. International Federation for Information Processing, 2012.

[15] Prasad, Rajkishore, Kumar Rajeev Ranjan, and A. K. Sinha. "AMRAPALIKA: An expert system for the diagnosis of pests, diseases, and disorders in Indian mango." Knowledge-Based Systems, Vol. 19, no. 1,pp. 9-21,2006.

[16] Sarma, Shikhar Kr, Kh Robindro Singh, and Abhijeet Singh. "An Expert System for diagnosis of diseases in Rice Plant." International Journal of Artificial Intelligence, Vol. 1, no. 1 ,pp. 26-31,2010, , 
[17] Balleda, Kaliuday, D. Satyanvesh, N. V. S. S. P. Sampath, K. T. N. Varma, and P. K. Baruah. "Agpest: An efficient rule-based expert system to prevent pest diseases of rice and wheat crops." In Intelligent Systems and Control ISCO, 2014 IEEE 8th International Conference on, pp. 262-268. IEEE, 2014.

[18] Negid, N. K. "Expert System for Wheat Yields Protection in Egypt ESWYP." International Journal of Innovative Technology and Exploring Engineering IJITEE, ISSN ,pp. 2278-3075,2014.

[19] Kaura, Ramanjeet, Salam Dina, and P. P. S. Pannub. "Expert System to Detect and Diagnose the Leaf Diseases of Cereals." Int $\mathrm{J}$ of Current Engineering and Technology, Vol. 3, no. 4, 2013.

[20] Kortuem, Gerd, Fahim Kawsar, Daniel Fitton, and Vasughi Sundramoorthy. "Smart objects as building blocks for the internet of things." Internet Computing, IEEE 14, no. 1 ,pp. 44-51,2010.

[21] Coetzee, Louis, and Johan Eksteen. "The Internet of Things-promise for the future? An introduction." In IST-Africa Conference Proceedings, 2011, pp. 1-9. IEEE, 2011.

[22] Ashton, Kevin. "That 'internet of things' thing." RFiD Journal, Vol. 22, no. 7 ,pp.97-114,2009.

[23] Chase, Jim. "The evolution of the internet of things." Texas Instruments ,2013.

[24] Travis, J. W., E. Rajotte, R. Bankert, K. D. Hickey, L. A. Hull, V. Eby, P. H. Heinemann, R. Crassweller, and J. McClure. "Penn State apple orchard consultant: design and function of the pest management module." In III International Symposium on Computer Modelling in Fruit Research and Orchard Management 313, pp. 209-214. 1992.

[25] Salah, A., H. Hassan, K. Tawfik, I. Ibrahim, and H. Farahat. "CITEX: an expert system for citrus crop management." In Proceedings of the Second National Expert Systems and Development Workshop ESADW93. 1993.

[26] El-Dessouki, A., S. Edrees, and S. El-Azhari. "CUPTEX: An integrated expert system for crop management of cucumber." ESADW-93, May ,1993.

[27] Mohammed, M., K. EI-Arby, and A. Rafea. "LIMEX: an integrated expert system for lime crop management." In Second IFAC/IFIP Enr AGENG Workshop on AI in Agriculture, Netherlands. 1995.

[28] Plant, R. E., F. G. Zalom, J. A. Young, and R. E. Rice. "CALEX/Peaches, an expert system for the diagnosis of peach and nectarine disorders." HortScience ,Vol. 24, no. 4 ,1989.
[29] Ferguson, James J., Fedro S. Zazueta, and Juan I. Valiente. "Citpath: diagnostic and hypertext software for fungal diseases of citrus foliage and fruit." HortScience, Vol. 30, no. 4 ,pp. 899-899,1995.

[30] Rani, Mercy Nesa, and Thangaswamy Rajesh. "Comparative Analysis on Software's used in Expert System with Special Reference to Agriculture." MANAGEMENT, Vol.2, no. 8.

[31] Saini, Harvinder S., Raj Kamal, and A. N. Sharma. "Web based fuzzy expert system for integrated pest management in soybean." International Journal of Information Technology ,Vol. 8, no. 1 ,pp.55-74, 2002.

[32] Babu, MS Prasad. "A web based tomato crop expert information system based on artificial intelligence and machine learning algorithms." ,2010.

[33] Qirui, Yin. "Kaas-based intelligent service model in agricultural expert system." In Consumer Electronics, Communications and Networks CECNet, 2012 2nd International Conference on, pp. 2678-2680. IEEE, 2012.

[34] Khan, Fahad Shahbaz, Saad Razzaq, Kashif Irfan, Fahad Maqbool, Ahmad Farid, Inam Illahi, and T. Ul Amin. "Dr. Wheat: a Web-based expert system for diagnosis of diseases and pests in Pakistani wheat." In Proceedings of the World Congress on Engineering, Vol. 1, pp. 2-4. 2008.

[35] Edrees, Soliman A., Ahmed Rafea, Ibrahim Fathy, and Mohamed Yahia. "NEPER: a multiple strategy wheat expert system." Computers and electronics in agriculture, Vol. 40, no. 1,pp. 27-43,2007.

[36] Gonzalez-Andujar, J. L., C. Fernandez-Quintanilla, J. Izquierdo, and J. M. Urbano. "SIMCE: An expert system for seedling weed identification in cereals." Computers and electronics in agriculture,Vol. 54, no. 2 ,pp.115-123,2006.

[37] Marchal, P. Cano, D. Martínez Gila, J. Gámez García, and J. Gómez Ortega. "Expert system based on computer vision to estimate the content of impurities in olive oil samples." Journal of Food Engineering , Vol.119, no. 2 ,pp. 220-228,2013.

[38] Kaloudis, S., D. Anastopoulos, Constantine P. Yialouris, Nikos A. Lorentzos, and Alexander B. Sideridis. "Insect identification expert system for forest protection." Expert Systems with Applications, Vol. 28, no. 3, pp. 445-452,2005.

[39] Mansingh, Gunjan, Han Reichgelt, and Kweku-Muata Osei Bryson. "CPEST: An expert system for the management of pests and diseases in the Jamaican coffee industry." Expert systems with Applications ,Vol.32, no. 1,pp. 184-192,2007. 